九州大学学術情報リポジトリ

Kyushu University Institutional Repository

\title{
Semiconductor nanopores formed by chemical vapor deposition of heteroepitaxial SiC films on SOI(100) substrates
}

Ikoma, Yoshifumi

Department of Materials Science and Engineering, Kyushu University

Yahaya, Hafizal

Department of Science, Universiti Teknologi Malaysia, International Campus I Department of Materials Science and Engineering, Kyushu University

Kur i yama, Ke i j i

Department of Materials Science and Engineering, Kyushu University

Sakita, Hirofumi

Department of Materials Science and Engineering, Kyushu University

他

http://hdl. handle. net/2324/25886

出版情報: Journal of Vacuum Science and Technology B : Microelectronics and Nanometer Structures. 29 (6), pp.062001(1)-062001(5), 2011-11. American Vacuum Society

バージョン :

権利関係: (C) 2011 American Vacuum Society 


\title{
Semiconductor nanopores formed by chemical vapor deposition of heteroepitaxial SiC films on SOI(100) substrates
}

\author{
Yoshifumi Ikoma $^{\text {a) }}$ \\ Department of Materials Science and Engineering, Kyushu University, 744 Motooka, Fukuoka 819-0395, Japan \\ Hafizal Yahaya \\ Department of Materials Science and Engineering, Kyushu University, 744 Motooka, Fukuoka 819-0395, Japan \\ and Department of Science, Universiti Teknologi Malaysia, International Campus, 54100 Jalan Semarak, Kuala \\ Lumpur, Malaysia \\ Keiji Kuriyama, Hirofumi Sakita, and Yuta Nishino \\ Department of Materials Science and Engineering, Kyushu University, 744 Motooka, Fukuoka 819-0395, Japan \\ Teruaki Motooka \\ Department of Materials Science and Engineering, Kyushu University, 744 Motooka, Fukuoka 819-0395, Japan \\ and Kyushu University Cleanroom Laboratory Facility, 8-7 Yayoigaoka, Tosu, Saga 841-0005, Japan \\ ${ }^{a)}$ Electronic mail: ikoma@zaiko.kyushu-u.ac.jp
}

We investigated the formation of nanometer-scale pore (nanopore) arrays by chemical vapor deposition (CVD) of heteroepitaxial $\mathrm{SiC}$ films on $\mathrm{Si}(100)$ membranes prepared by anisotropic etching of silicon on insulator substrates from the backside surfaces. $\mathrm{SiC}$ heteroepitaxial films with thicknesses of $\sim 10 \mathrm{~nm}$ were grown by pulse jet CVD of $\mathrm{CH}_{3} \mathrm{SiH}_{3}$ gas. During the $\mathrm{SiC}$ growth, inverted pyramidal pits with $\{111\}$ facets grew into the Si membranes due to the surface diffusion of Si atoms outward from the bulk Si. Nanopores were formed at the tips of the inverted pyramidal pits. The pore sizes were found to be dependent on the existence of the buried oxide layers under the Si membranes. It is suggested that maintaining the $\{111\}$ facets during the $\mathrm{SiC}$ growth on the $\mathrm{Si}$ membrane is essential for smaller size $(\sim \mathrm{nm})$ pore formation.

PACS: 81.07.-b, 81.15.-z, 81.15.Gh, 81.16.-c, 81.65.Cf, 61.43.Gt 


\section{INTRODUCTION}

Nanometer-sized pores (nanopores) based devices have attracted great interest in molecular sensors such as DNA sequencers. ${ }^{1-3}$ Recently, individual molecules of double-stranded DNA and their folding behavior have been successfully observed by a nanopore microscope. ${ }^{4}$ Robustness of nanopores on membrane materials is essential for development of high-performance nanopore DNA sequencers. Nanopore devices have been mostly constructed with biopolymers and solid-state materials. Many of the biopolymer based devices have been fabricated with $\alpha$-hemolysin for translocation of DNA molecules. ${ }^{5-8}$ However, there are some limitations for such biopolymer based devices in terms of size and stability. ${ }^{1,4,8}$ Ion beam sculpting is often utilized for solid-state nanopore fabrication in silicon nitride ${ }^{9,10}$ and $\mathrm{SiO}_{2}{ }^{10}$ membranes. Nanopore formations by high energy electron beam exposure on $\mathrm{SiO}_{2}{ }^{11}$ and $\mathrm{Al}_{2} \mathrm{O}_{3}{ }^{12}$ membranes have also been reported. Robust and precise nanopores can be successfully obtained by these solid-state techniques, however, they are not suitable for mass production yet.

Silicon carbide $(\mathrm{SiC})$ is a wide band gap semiconductor which has many promising properties for applications in high-performance electronic devices. ${ }^{13}$ When SiC films are grown on Si substrates by chemical vapor deposition (CVD), thin epitaxial $\mathrm{SiC}$ layers are often formed by consuming $\mathrm{Si}$ atoms from the substrates. ${ }^{14}$ This process results in the formation of numerous pits having $\operatorname{Si}\{111\}$ facets which are randomly formed at the $\mathrm{SiC} / \mathrm{Si}$ interfaces. $^{15,16}$ Previously, we have reported the $\mathrm{SiC}$ heteroepitaxial growth on $\mathrm{Si}(100)$ and the formation of $\{111\}$ faceted pits by supersonic pulse jet CVD (SPJ-CVD) using organosilicon gases such as $\mathrm{Si}\left(\mathrm{CH}_{3}\right)_{4}{ }^{17}$ and $\mathrm{CH}_{3} \mathrm{SiH}_{3}{ }^{18,19}$ at $900{ }^{\circ} \mathrm{C}$ without a high temperature carbonization process. Recently, we have also reported a novel method for the fabrication of nanopores utilizing these pits in the top-Si layers of separation by implanted oxygen (SIMOX) (100) substrates during ultrathin $(\sim 10 \mathrm{~nm}) \mathrm{SiC}$ film growths. ${ }^{20}$ SPJ-CVD can precisely control the film thickness, and the nanopore formation can be achieved by adjusting the pulse width, frequency, and the total pulse number. However, the mechanism of 
the nanopore formation utilizing these pits on Si membranes has not been fully understood.

In this study, we further investigated the formation of nanopore arrays by utilizing the $\mathrm{SiC}$ growths on $\mathrm{Si}(100)$ membranes obtained by anisotropic etching of silicon on insulator (SOI) (100) substrates. Effects of the $\mathrm{SiO}_{2}$ layers under the $\mathrm{Si}$ membrane layers on nanopore formation were examined by electron microscopy.

\section{EXPERIMENTAL PROCEDURE}

Figure 1 shows the flow process for the fabrication of our nanopores. We used SOI(100) substrates with a top Si layer thickness and a buried oxide (BOX) layer thickness of 5 and $1.5 \mu \mathrm{m}$, respectively. The thickness of the handle wafers was $380 \mu \mathrm{m}$. The backsides of the wafers had $1 \mu \mathrm{m}$ thick $\mathrm{SiO}_{2}$ layers. These substrates were cut into $20 \times 20 \mathrm{~mm}^{2}$ square pieces. The thickness of the top Si layer was reduced to $0.4 \mu \mathrm{m}$ first by wet etching with $22 \%$ tetramethyl ammonium hydroxide (TMAH) at $60{ }^{\circ} \mathrm{C}$ for 23 hours. After the reduction of the top $\mathrm{Si}$ layer, $0.4 \mu \mathrm{m}$ thick $\mathrm{SiO}_{2}$ layer was formed on the top $\mathrm{Si}$ layer by thermal oxidation in dry $\mathrm{O}_{2}$ atmosphere at $1100{ }^{\circ} \mathrm{C}$. By these etching and oxidation processes, the thickness of the top Si layer was reduced to $\sim 0.2 \mu \mathrm{m}$ [Fig. 1(a)]. Photoresist coatings were applied to both surfaces of the wafers after the Si thickness reduction. On the backside, the photoresist film was applied with $\sim 450 \mu \mathrm{m}$ square openings separated by $\geq 2 \mathrm{~mm}$. These square patterns were etched onto the backside $\mathrm{SiO}_{2}$ layer in $5 \%$ buffered $\mathrm{HF}$ (BHF) solution [Fig. 1(b)]. After removing both photoresist layers, anisotropic etching to remove all Si from the backside of the SOI substrate within the square openings was carried out using TMAH solution ${ }^{21,22}$ at $75{ }^{\circ} \mathrm{C}$. The remaining $\mathrm{Si}$ membranes were sandwiched between the front-side $\mathrm{SiO}_{2}$ and the BOX layers as shown in Fig. 1(c).

We utilized two different configurations of the Si membranes for the nanopore formations in this work. In the first approach, $\mathrm{SiC}$ was epitaxially grown on the $\mathrm{Si}$ membranes after the front-side $\mathrm{SiO}_{2}$ and the $\mathrm{BOX}$ layers were completely etched in the square regions as shown in Figs. 1(d) and 1(e). In the second approach, SiC was grown with BOX layers still 
left intact [Fig. 1(f)-1(h)]. The sample shown in Fig. 1(c) was dipped in BHF solution and both the front-side $\mathrm{SiO}_{2}$ and the $\mathrm{BOX}$ layers were completely removed to produce $\mathrm{Si}$ membranes existing completely free in the $\sim 450 \mu \mathrm{m}$ square openings as shown in Fig. 1(d). The back-side $\mathrm{SiO}_{2}$ layer was also etched and removed at the same time. Finally, nanopore arrays were obtained after the $\mathrm{SiC}$ growth and the pit formation in the Si membranes as shown in Fig. 1(e). In the second approach, we applied the same method which was previously used for the nanopore formation on $\operatorname{SIMOX}(100) .{ }^{20}$ The $\mathrm{SiO}_{2}$ layer at the front side of Fig. 1(c) was completely removed after dipping in $\mathrm{BHF}$ solution. The backside $\mathrm{SiO}_{2}$ and the $\mathrm{BOX}$ layers were partially etched during this process, but were not removed completely as shown in Fig. 1(f). Inverted pyramidal pits were formed in the $\mathrm{Si}$ membranes by the $\mathrm{SiC}$ growths as shown in Fig. 1(g). Finally, nanopore arrays were obtained after the BOX layer under the pits was removed by BHF etching [Fig. 1(h)].

All $\mathrm{SiC}$ growths were carried out using a SPJ-CVD system ${ }^{23}$ equipped with a supersonic pulse valve having a nozzle diameter of $0.8 \mathrm{~mm}$. The details are described elsewhere. ${ }^{18}$ The substrate was placed on a molybdenum holder, which had a film growth area of $15 \times 15 \mathrm{~mm}^{2}$ square, and was heated to $900{ }^{\circ} \mathrm{C}$ by a tantalum heater. $\mathrm{SiC}$ films were formed on the top $\mathrm{Si}$ layer by irradiating electronic grade $\mathrm{CH}_{3} \mathrm{SiH}_{3}$ pulse jets. The pulse width and frequency were set at $100 \mu \mathrm{s}$ and $5 \mathrm{~Hz}$, respectively. All SiC films were grown with 9000 pulses of $\mathrm{CH}_{3} \mathrm{SiH}_{3}$ jets and resulted in a typical thickness of $10 \mathrm{~nm}$. The samples were characterized by transmission electron microscopy (TEM) and scanning electron microscopy (SEM).

\section{RESULTS AND DISCUSSION}

In order to confirm that there are no pits or pores formed during the formation of $\mathrm{Si}$ membranes without BOX as shown in Fig. 1(d), we carried out anisotropic etching of the $\mathrm{SOI}(100)$ substrate from the backside surface and removed the BOX layer under the top Si layer. Figure 2 shows SEM images of the Si membrane which was obtained by TMAH 
etching for 23 hours followed by 30 min BHF etching. The plan view image of Fig. 2(a) indicates that the Si handle wafer is anisotropically etched forming four $\{111\}$ facets. No appreciable pits or nanopores are observed in the Si membrane before the deposition of SiC. The cross-sectional images in Fig. 2(b) show that the thickness of the Si membrane is reduced to $\sim 0.2 \mu \mathrm{m}$.

Figure 3 shows bright and dark field TEM images and a diffraction pattern of the $\mathrm{Si}$ membrane after the SiC film growth. This diffraction pattern, Fig. 3(a), indicates that a single crystalline $3 \mathrm{C}-\mathrm{SiC}$ film is heteroepitaxially grown on the $\mathrm{Si}(100)$ membrane. The bright-field image, Fig. 3(b), shows that the $\{111\}$ faceted pyramidal structures disappear and the resulting pore shapes are irregular with a size of $\sim 0.5 \mu \mathrm{m}$. Dark field images, which are taken with $\mathrm{Si}$ and $\mathrm{SiC} 022$ diffraction spots, respectively, are presented in Figs. 3(c) and 3(d). The pores appear bright in the bright field image, Fig. 3(b), and dark in the Si 022 dark field image, Fig. 3(d). Thinner films are found attached at the edges of these pores, and can be clearly seen in Fig. 3(b). Such films are also recognizable in the $\mathrm{SiC} 022$ dark field image indicating that these very thin films are $\mathrm{SiC}$ overgrown on the pores. The formation of these pores indicates that the mechanism of the pit growth in the Si membranes is different from those observed in $\operatorname{SIMOX}(100) .{ }^{20}$ The details will be discussed later.

Figure 4 shows SEM images of a sample which were obtained by the second approach with the BOX layer still left under the Si membrane layer. After the SiC film growth, carried out under the same condition described above for the first approach, the BHF etching was performed for $30 \mathrm{~min}$ in order to remove the BOX layer under the pits for this sample. This last etching process completes the formation of nanopores. The formation of circular patterns with the diameter of $\sim 3 \mu \mathrm{m}$ on the SOI(100) surface in Fig. 4(a) indicates that nanopores are formed by concentric etching of the BOX layer through the pits which are large enough to reach the BOX layer below the pits. ${ }^{20}$ Higher magnification images of the SOI(100) surface and the Si membrane are shown in Figs. 4(b) and 4(c), respectively. Fig. 4(b) shows that the formation of pits, similar in appearance to bell shaped nozzles in rocket engines, 
having diameters of $\leq 1 \mu \mathrm{m}$ at the top and $\sim 3 \mu \mathrm{m}$ at the bottom. The pit density in Fig. $4(\mathrm{~b})$ is estimated to be $9 \times 10^{6} / \mathrm{cm}^{2}$. The pit density on the Si membrane side shown in Fig. 4(c) is 8 $\times 10^{6} / \mathrm{cm}^{2}$, which is comparable to that in Fig. 4(b). Actual pores formed at the bottom of the Si membrane appear dark in Fig. 4(c) and a TEM image of one of these pores is given in Fig. 5. The TEM diffraction pattern and the dark-field image in Fig. 5 show that a square pit with the width of $370 \mathrm{~nm}$ at its base and a rectangular nanopore opening with a width of $\sim 20 \mathrm{~nm}$ was formed by $\mathrm{SiC}$ heteroepitaxial growth on the $\mathrm{Si}(100)$ membrane.

The pore sizes became larger $(\sim 0.5 \mu \mathrm{m})$ in the first approach, while smaller $(\sim 20 \mathrm{~nm})$ nanopores were obtained in the center of the $\{111\}$ faceted pits in the second approach. The difference in the resulting pore sizes may be explained as follows. For both cases, SiC films are epitaxially grown on the top $\mathrm{Si}$ layers incorporating $\mathrm{Si}-\mathrm{C}$ bonded radicals existing in $\mathrm{CH}_{3} \mathrm{SiH}_{3}$ molecules. The film growth is accompanied by the formation of inverted pyramidal $\{111\}$ faceted pits at the $\mathrm{SiC} / \mathrm{Si}$ interface. The pit formation is attributed to the fact that $\mathrm{Si}$ diffusion from the substrate creates a Si-rich reaction environment on the surface until the growing SiC film seals off the diffusion channels in the growth from $\mathrm{CH}_{3} \mathrm{SiH}_{3}$ gas source. ${ }^{24}$ The $\{111\}$ faceted pits grow deeper and eventually the tips of the inverted pyramidal pits reach the bottom of the Si membrane. When the tips of these inverted pyramidal pits penetrate through the Si membrane, the Si atoms may well preferentially diffuse outward at the edges of these pits in the case of the first approach. The increase in the total surface area enhances the expansion of the pore sizes, because surface diffusion coefficient of $\mathrm{Si}$ atoms at $900{ }^{\circ} \mathrm{C}$ is in the order of $10 \mu \mathrm{m}^{2} / \mathrm{s},{ }^{25}$ while it is in the order of $10^{-10} \mu \mathrm{m}^{2} / \mathrm{s}$ in the bulk. ${ }^{26}$ Strains induced by possible mechanical deformations of the $\mathrm{Si}$ membrane may also affect the diffusion of interstitial $\mathrm{Si}$ atoms in bulk $\mathrm{Si}$, since the membrane is free standing without the BOX layer attached in the first approach. Consequently, the $\{111\}$ facets disappear and the pits no longer have the same aspect ratio. Expanded pores are formed as schematically shown in Fig. 6(a) in the first approach. The existence of the BOX layer acts as a barrier against the diffusion of Si atoms at the tips of the pits because the dissociation energy of $\mathrm{Si}-\mathrm{O}$ bond $(535.6 \mathrm{~kJ} / \mathrm{mol})$ is 
much higher than that of Si-Si bond $(225.9 \mathrm{~kJ} / \mathrm{mol})^{27}$ in the second approach. In addition, the existence of the BOX layer may suppress the mechanical deformation of the Si membrane. Thus, the outward diffusion of the Si membrane layer atoms is similar in magnitude to that of bulk Si even after the tips of the inverted pyramidal pits reach the BOX layer. Möller et al. reported the pit or cavity formation during the epitaxial growth of $3 \mathrm{C}-\mathrm{SiC}$ on $\mathrm{SOI}$ substrates at $1200{ }^{\circ} \mathrm{C}$ and found that cavities took a cylindrical shape, and then were extended laterally when they penetrated to touch the BOX layer. ${ }^{28}$ Since the Si diffusion rate is minimal at the relatively low $\mathrm{SiC}$ growth temperature of $900{ }^{\circ} \mathrm{C}$ in our experimental condition, the shape of the $\{111\}$ faceted pits is maintained as shown in Fig. 6(b) in the second approach. These results suggest that the pit formation in the Si membrane with the BOX layer at low substrate temperatures is essential for the formation of smaller nanopores, and may present a way to control the pore sizes in nanometer scales.

\section{CONCLUSION}

We have demonstrated the formation of nanopore arrays on SOI substrates by $\mathrm{SiC} / \mathrm{Si}$ heteroepitaxial growths by $\mathrm{CH}_{3} \mathrm{SiH}_{3}$ pulse jet CVD. The backside $\mathrm{Si}$ was removed completely by anisotropic etching, and the BOX layer was also etched either completely or partially. In the nanopore formation in the Si membrane without the BOX layer beneath, $\{111\}$ faceted pits disappeared, and pores with a size of $\sim 0.5 \mu \mathrm{m}$ were formed. Nanopores with an average pore size of $\sim 20 \mathrm{~nm}$ were obtained on the Si membrane with the BOX layer still attached. The existence of the BOX layer under the Si membranes in addition to the low temperature $\mathrm{SiC}$ growth process are important in the nanopore formation. This in turn may present ways to control the resulting nanopore sizes by adjusting such parameters as the thicknesses of both the top $\mathrm{Si}$ and the BOX layers as well as the CVD conditions.

\section{ACKNOWLEDGMENTS}

The authors would like to thank Dr. Fumiya Watanabe of University of Arkansas at Little Rock for invaluable discussions. This research was supported by the Ministry of 
Education, Science, Sports and Culture, Grant-in-Aid for Young Scientists (B) No. 20760495. 


\section{References}

${ }^{1}$ D. W. Deamer and M. Akeson, Trends. Biotechnol. 18, 147 (2000).

${ }^{2}$ O. A. Saleh and L. L. Sohn, Nano Lett. 3, 37 (2003).

${ }^{3}$ M. Rhee and M. A. Burns, Trends. Biotechnol. 24, 580 (2006).

${ }^{4}$ J. Li, M. Gershow, D. Stein, E. Brandin, and J. A. Golovchenko, Nature Mater. 2, 611 (2003).

${ }^{5}$ J. J. Kasianowicz, E. Brandin, D. Branton, and D. W. Deamer, Proc. Natl. Acad. Sci. U.S.A. 93, 13770 (1996).

${ }^{6}$ M. Akeson, D. Branton, J. J. Kasianowicz, E. Brandin, and D. W. Deamer, Biophys. J. 77, 3227 (1999).

${ }^{7}$ A. Meller, L. Nivon, and D. Branton, Phys. Rev. Lett. 86, 3435 (2001).

${ }^{8}$ D. W. Deamer and D. Branton, Acc. Chem. Res. 35, 817 (2002).

${ }^{9}$ J. Li, D. Stein, C. McMullan, D. Branton, M. J. Aziz, and J. A. Golovchenko, Nature 412, 166 (2001).

${ }^{10}$ D. Stein, J. Li, and J. A. Golovchenko, Phys. Rev. Lett. 89, 276106 (2002).

${ }^{11}$ A. J. Storm, J. H. Chen, X. S. Ling, H. W. Zandbergen, and C. Dekker, Nature Mater. 2, 537 (2003).

${ }^{12}$ B. M. Venkatesan, B. Dorvel, S. Yemenicioglu, N. Watkins, I. Petrov, and R. Bashir, Adv. Mater. 21, 2771 (2009).

${ }^{13}$ R. F. Davis, G. Kelner, M. Shur, J. W. Palmour, and J. A. Edmond, Proc. IEEE 79, 677 (1991).

${ }^{14}$ S. Nishino, J. A. Powell, and H. A. Will, Appl. Phys. Lett. 42, 460 (1983).

${ }^{15}$ J. P. Li and A. J. Steckl, J. Electrochem. Soc. 142, 634 (1995).

${ }^{16}$ L.-O. Björketun, L. Hultman, I. P. Ivanov, Q. Wahab, and J.-E. Sundgren, J. Cryst. Growth 182, 379 (1997).

${ }^{17}$ Y. Ikoma, T. Endo, F. Watanabe, and T. Motooka, J. Vac. Sci. Technol. A 16, 763 (1998).

${ }^{18}$ Y. Ikoma, T. Endo, F. Watanabe, and T. Motooka, Jpn. J. Appl. Phys. Part 2 38, L301 (1999).

${ }^{19}$ Y. Ikoma, T. Endo, F. Watanabe, and T. Motooka, Appl. Phys. Lett. 75, 3977 (1999). 
${ }^{20}$ Y. Ikoma, K. Ono, M. Uenuma, T. Ogata, and T. Motooka, Proc. SPIE 6984, 69841V (2008).

${ }^{21}$ O. Tabata, R. Asahi, H. Funabashi, K. Shimaoka, and S. Sugiyama, Sens. Actuators A 34, 51 (1992).

${ }^{22}$ P.-H. Chen, H.-Y. Peng, C.-M. Hsieh, and M. K. Chyu, Sens. Actuators A 93, 132 (2001).

${ }^{23}$ T. Motooka, H. Abe, P. Fons, and T. Tokuyama, Appl. Phys. Lett. 63, 3473 (1993).

${ }^{24}$ K. S. Ziemer, A. A. Woodworth, C. Y. Peng, and C. D. Stinespring, Diamond Relat. Mater. 16, 486 (2007).

${ }^{25}$ M. E. Keeffe, C. C. Umbach, and J. M. Blakely, J. Phys. Chem. Solids 55, 965 (1994).

${ }^{26}$ H. Bracht, E. E. Haller, and R. Clark-Phelps, Phys. Rev. Lett. 81, 393 (1998).

${ }^{27}$ G. Raabe and J. Michl, Chem. Rev. 85, 419 (1985).

${ }^{28}$ H. Möller, G. Krötz, M. Eickhoff, A. Nielsen, V. Papaioannou, and J. Stoemenos, J. Electrochem. Soc. 148, G16 (2001). 
Figure captions

FIG. 1. (Color online) Process flow for the fabrication of nanopores: (a) wet etching of the top Si layer and thermal oxidation, (b) photolithography and BHF etching of the backside surface, and (c) anisotropic etching of the handle wafer. For the nanopore formation in Si membranes without BOX (the first approach), (d) the sample was dipped into BHF solution, then (e) SiC growth accompanying pit formation was carried out from the front side surface. In the case of the nanopore formation utilizing Si membranes with BOX (the second approach), (f) the BOX layer was partially etched by BHF solution, (g) SiC growth and pit formation were carried out from the front side surface, and (h) the BOX layer was removed by BHF etching to expose the nanopores.

FIG. 2. (Color online) (a) plan view and (b) cross-sectional SEM images of the Si membrane obtained by TMAH etching for 23 hours, and following BHF etching for 30 min. Right side images in (a) and (b) show the magnified images of the regions enclosed by the solid square/rectangle. Under the exposed Si membrane, the BOX layer was completely etched, and is marked as "air gap" within the $\sim 450 \mu \mathrm{m}$ square in (b).

FIG. 3. TEM (a) diffraction pattern, (b) bright-field image, and (c), (d) dark-field images of the pores formed by the first approach in which $\mathrm{SiC}$ epitaxial growth was carried out on $\mathrm{Si}$ membranes without BOX. The dark-field images of (c) and (d) were taken by using Si and $\mathrm{SiC} 022$ diffraction spots which corresponded to the arrows (c) and (d), respectively, in the diffraction pattern of (a).

FIG. 4. (Color online) (a) Typical SEM images of the sample surfaces obtained by the second approach in which $\mathrm{SiC}$ growth was carried out on $\mathrm{Si}$ membranes without BOX: (a) $\mathrm{Si}$ membrane enclosed by the white broken lines, (b) and (c) magnified images of SOI(100) surface and Si membrane, respectively. Schematic views of the nanopores on the SOI(100) 
surface region and the Si membrane are shown in (b) and (c), respectively, to aid in the interpretation of these SEM images.

FIG. 5 TEM diffraction pattern and dark-field image of the same sample shown in Fig. 4. This dark-field image was taken by using one of the Si 022 diffraction spots.

FIG. 6 (Color online) Schematic diagrams of the pit formations: (a) in the Si membrane without the BOX layer (the first approach), and (b) in the Si membrane with the BOX layer (the second approach). 
(a)

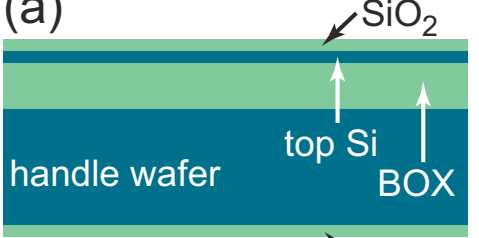

(b) photoresist $\mathrm{SiO}_{2}$

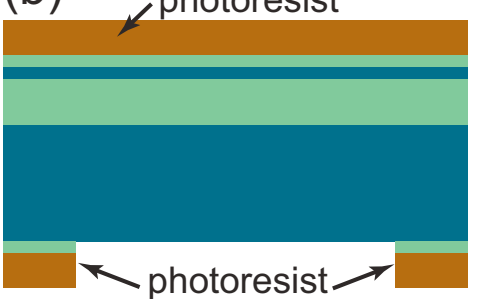

(c)

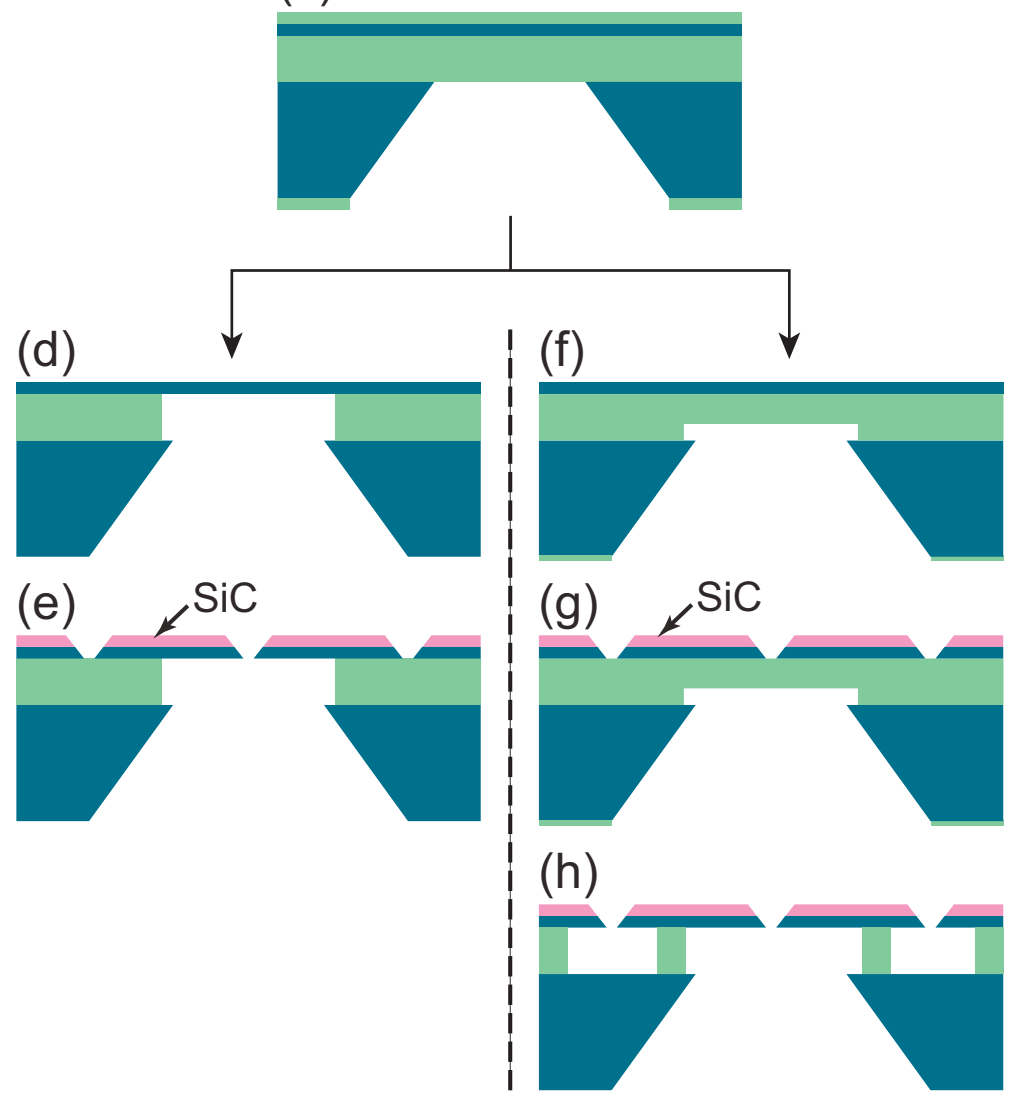


(a)

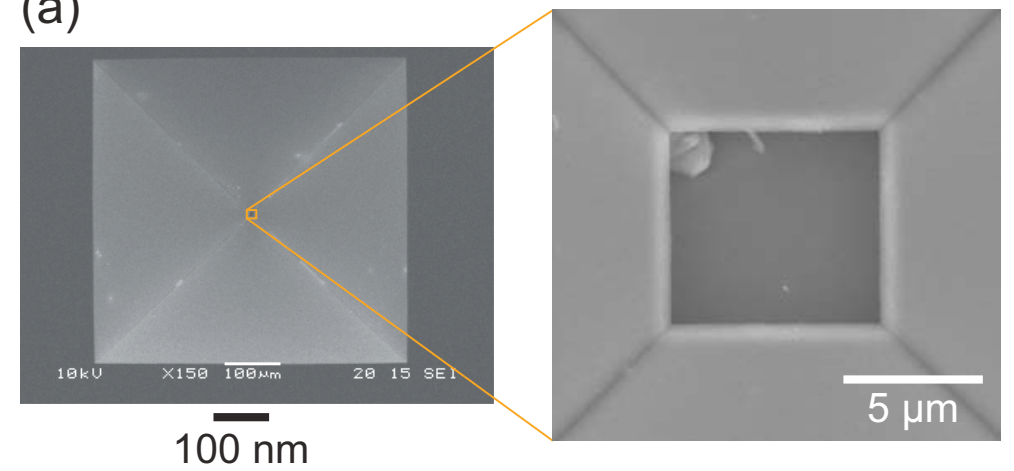

(b)

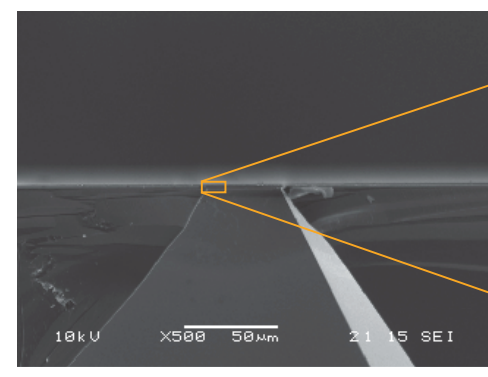

\begin{tabular}{lcl} 
& Si membrane \\
\hline BOX & air gap & \\
\hline $\begin{array}{l}\text { handle } \\
\text { wafer }\end{array}$ & & $1 \mathrm{\mu m}$
\end{tabular}

$\overline{50 \mu \mathrm{m}}$ 
(a)
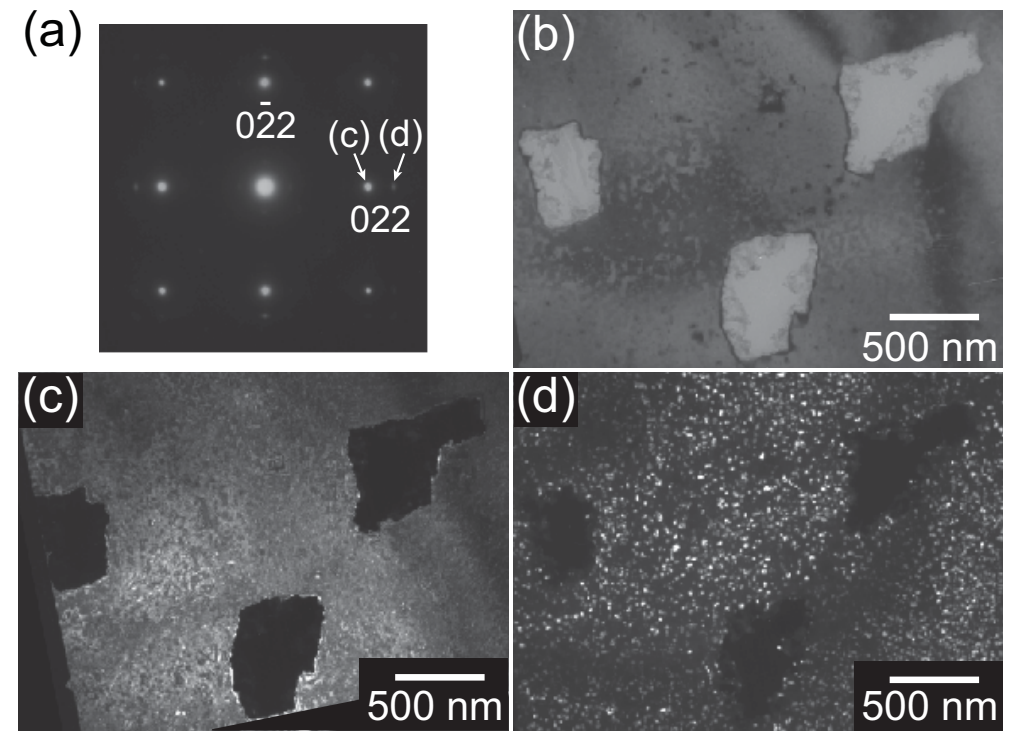
(a)

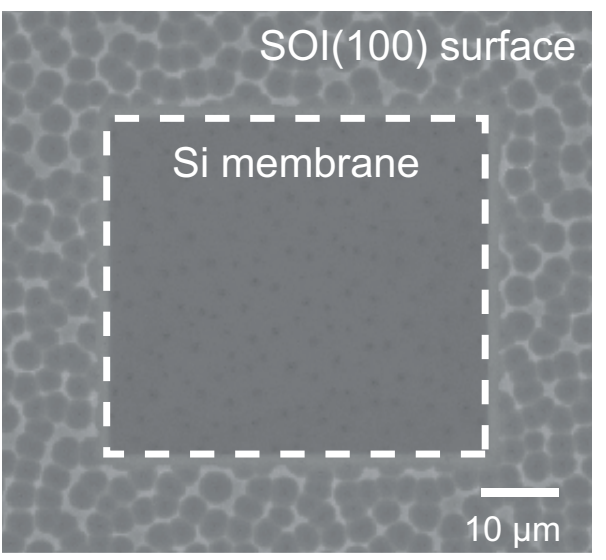

(b)

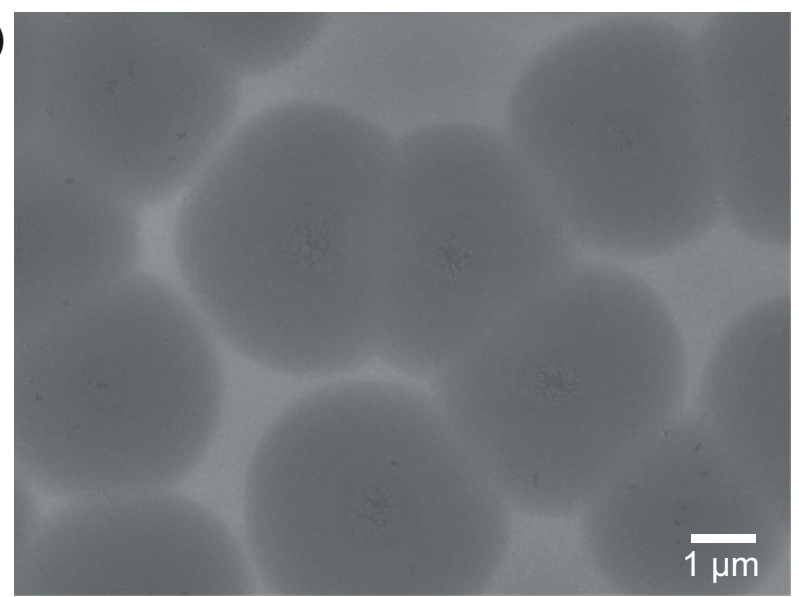

SEM observation

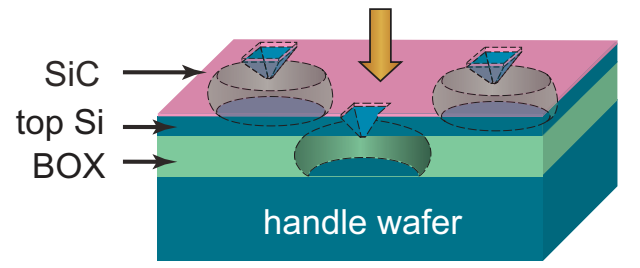

(c)

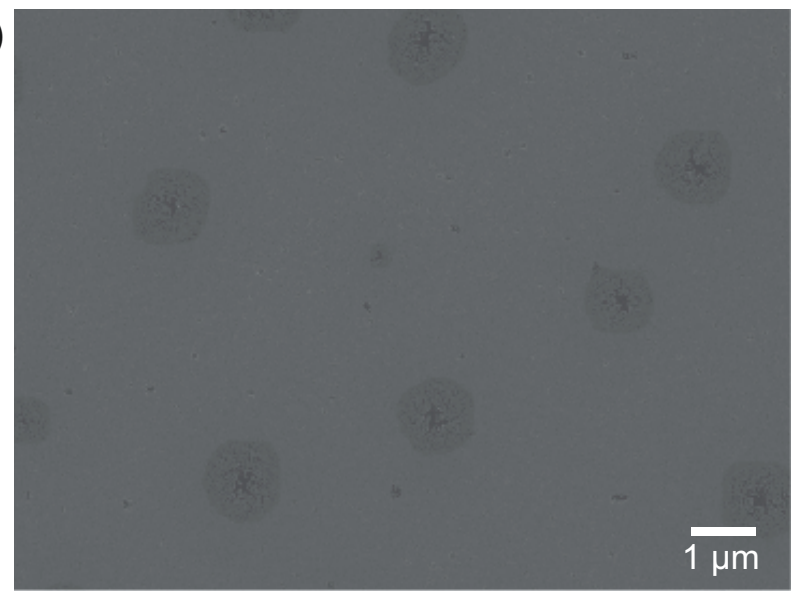

SEM observation

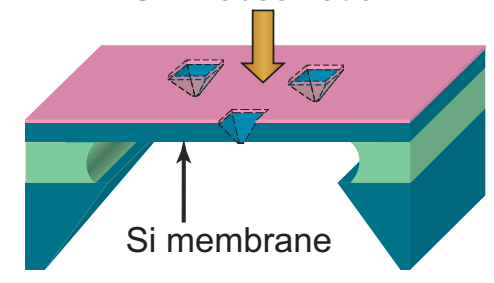




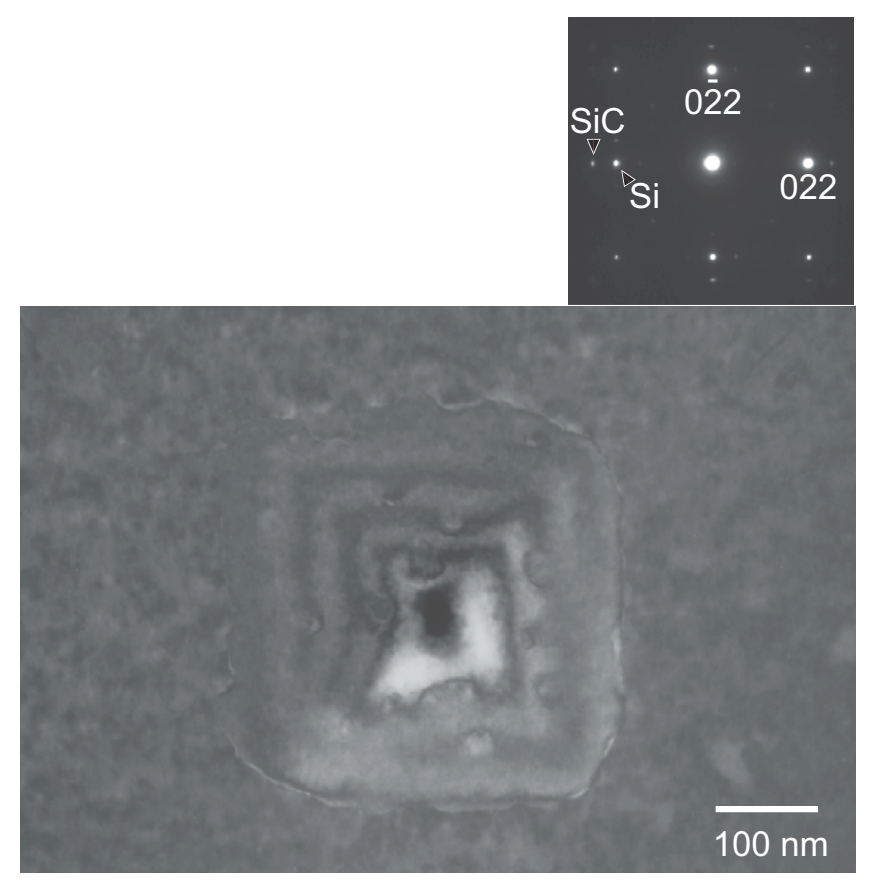


(a) $\mathrm{SiC}$

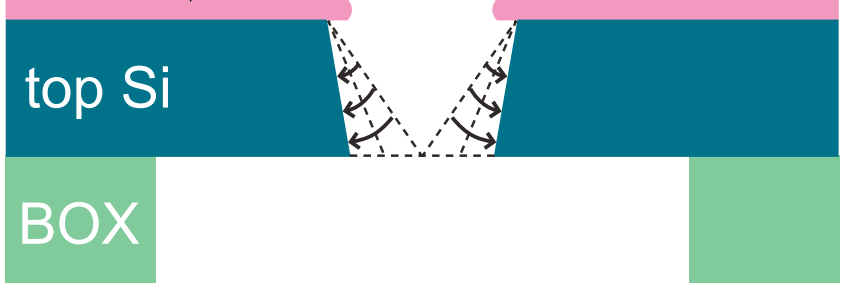

(b)

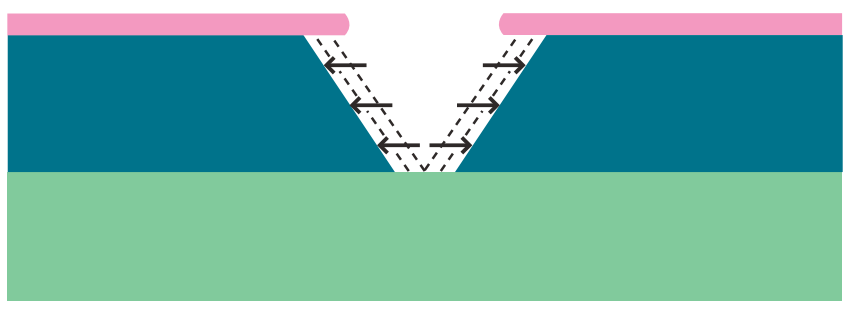

